\title{
Evaluation of Green Coffee-Roasting Biogas with Modeling Valorization of Possible Solutions
}

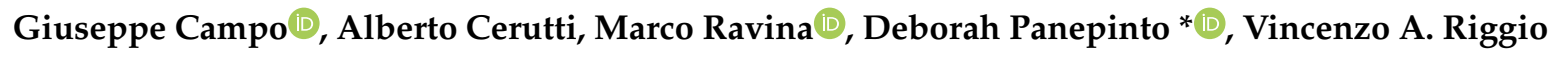 \\ and Mariachiara Zanetti \\ Department of Environment, Land and Infrastructure Engineering, Politecnico di Torino, 10129 Torino, Italy; \\ giuseppe.campo@polito.it (G.C.); alberto.cerutti@polito.it (A.C.); marco.ravina@polito.it (M.R.); \\ vincenzo.riggio@polito.it (V.A.R.); mariachiara.zanetti@polito.it (M.Z.) \\ * Correspondence: deborah.panepinto@polito.it; Tel.: +39-0110907660
}

Received: 4 September 2020; Accepted: 21 September 2020; Published: 23 September 2020

\begin{abstract}
According to the European Union Directive 2009/28/EC, the goals of obtaining 20\% of all energy requirements from renewable sources and a $20 \%$ reduction in primary energy use must be fulfilled by 2020. In this work, an evaluation was performed, from the environmental and energy point of view, of anaerobic digestion as a valid solution for the treatment of the byproducts obtained from the coffee-roasting process. In particular, thermophilic anaerobic digestion tests were carried out. Output values from the laboratory were used as input for the $\mathrm{MCBioCH}_{4}$ model to evaluate the produced flow of biogas and biomethane and two different biogas valorization alternatives, namely, the traditional exploitation of biogas for heat/energy production and biomethane conversion. The results of the preliminary simulation showed that a full-scale implementation of the coffee waste biogas production process is technically feasible and environmentally sustainable. Furthermore, the performed analysis validates a general methodology for energy production compatibility planning.
\end{abstract}

Keywords: anaerobic digestion; coffee; biomass; byproducts; circular economy; climate change; environmental impact

\section{Introduction}

In recent years, there has been an increasing trend toward the efficient utilization of byproducts [1,2]. In the last few years, the possibility of saving energy by using resources that are considered waste has become more and more attractive to commercial plant management. The concept of waste has just begun to change. Agroindustrial products are included in this evolving scenario. One of the major agroindustrial products in terms of consumed amounts is coffee. Coffee is the second most traded product on the world market after fuel. The coffee market generates enormous volumes of waste, causing considerable economic and environmental concerns [3].

The consumption of coffee as a drink has been a custom for over 1000 years. The product began to be enjoyed in Europe in 1615, brought by travelers. Europeans began to exploit colonial territories in order to develop large coffee plantations. Currently, the largest exporter of coffee beans in the world is Brazil, with 40 million bags of $60 \mathrm{~kg}$ produced per year, followed by Vietnam, Colombia, and Indonesia. Specifically, South America is responsible for $43 \%$ of the world's coffee production, followed by Asia with $24 \%$, Central America with $18 \%$, and Africa with $16 \%$. It is estimated that 400 billion cups of coffee are consumed every year. Despite the financial crisis at the beginning of this century, coffee consumption did not decrease. The only fact that can be observed after 2008 is the change in the chosen quality by consumers, which is lower than in previous years [3].

The word "coffee" more appropriately refers to a wide range of products: fresh fruit, green beans, roasted beans, beverages, and instant coffee [4]. The first treatment of the product takes place in 
exporting countries. The main residues of these processes are so-called coffee husks or coffee pulp; depending on the types of processing, the total amount of these two initial kinds of waste are equal to $53 \pm 12 \%$ of the total weight of the fresh fruit. Next, the processing continues in the industries of the purchasing countries, where coffee silver skin is another waste obtained from this kind of process, and it is equal to about $1 \pm 2 \%$. The remaining $45 \pm 10 \%$ of spent wastes come from brewing the coffee. One of the biggest buyers of this product is Italy, preceded by Germany and Belgium. Italy is also, in turn, one of the largest exporters of roasted coffee, counting more than 800 roasters throughout the country, which, in 2019, generated a sales revenue of about 3.9 billion euros [5].

There are three types of processing waste generated in coffee-roasting plants: Green coffee powder, pellets, and roasted coffee powder [5]. They are properly defined as lignocellulosic biomass due to the high dry content of vegetable origin. The exploitation and management of coffee byproducts have been applied to various areas and finds new applications. Table 1 contains a list of byproducts associated with one or more methods of utilization found in the literature. Applications such as those linked to the antioxidant and protein properties of waste in cosmetics and pharmaceuticals are not lacking. Particular attention should also be paid to the production of animal feed: the presence of caffeine may discourage its use; however, preparations containing coffee byproducts are considered positive if introduced as food supplements and not as a substitute for a normal animal diet. Recently, research has been developed concerning the use of coffee waste for the production of bioplastics. This process requires that the residues are treated with solvents or biocompatible polymers to obtain a malleable and versatile material that is completely biodegradable. The research is currently being carried out by the Italian Institute of Technology (IIT) [6]. There are also several reports on the production of polyhydroxyalkanoate (PHA) bioplastics from spent coffee grounds [7-9].

Of interest is also the extraction of oil, in particular, from coffee grounds coming from residues of drink production, to be used as fuel. The new British start-up Bio-Bean is developing the possibility of using this fuel as a biofuel for buses [10].

Table 1 shows that the most reliable and efficient technologies that have been considered for energy recovery from these types of materials are direct combustion and anaerobic digestion (AD) [11,12]. In fact, all kinds of residues of coffee production can be managed by these two main technologies. The analyzed matrices have a high lower heating value on the one hand and, on the other hand, they can also provide essential minerals for the growth of anaerobic bacteria [5].

Table 1. Methods of use of coffee byproducts.

\begin{tabular}{|c|c|c|c|c|c|}
\hline Utilization Methods & $\begin{array}{c}\text { Coffee Husks, } \\
\text { Pulp }\end{array}$ & $\begin{array}{l}\text { Green Coffee } \\
\text { Powder }\end{array}$ & Pellets & $\begin{array}{c}\text { Roasted Coffee } \\
\text { Powder }\end{array}$ & $\begin{array}{l}\text { Coffee } \\
\text { Grounds }\end{array}$ \\
\hline Combustion & [4] & [12] & [12] & {$[9,12]$} & [12] \\
\hline Anaerobic digestion & [12] & {$[12]$} & {$[12]$} & {$[9,12]$} & {$[12]$} \\
\hline $\begin{array}{l}\text { Substrate for the growth of edible } \\
\text { mushrooms }\end{array}$ & [4] & - & - & - & [3] \\
\hline $\begin{array}{l}\text { Feed for livestock as a supplement for } \\
\text { the diet of pigs, cattle, fish, sheep, } \\
\text { and poultry }\end{array}$ & [4] & - & - & - & - \\
\hline Fertilizers & [4] & - & - & - & [12] \\
\hline Preparation of activated carbon & [4] & - & - & - & - \\
\hline Biodiesel & - & - & - & - & {$[3,13]$} \\
\hline Pharmaceutical industries & - & - & {$[3]$} & - & - \\
\hline Cosmetic industries & - & - & [14] & - & - \\
\hline Bioethanol & - & - & - & - & [3] \\
\hline Production of a steak drink & - & - & - & - & [3] \\
\hline Insulation material for buildings & - & - & - & - & {$[12,15]$} \\
\hline Bioplastic & - & - & - & - & [14] \\
\hline
\end{tabular}

This work will evaluate anaerobic digestion as a possible alternative for the valorization of byproducts obtained from the coffee-roasting process $[16,17]$. The developed activity is a continuation of a previous study carried out by the same authors [5]. It should be emphasized that although the 
possible uses of all coffee byproducts are mentioned in the literature, there are few experiments on the roasting byproducts.

Different byproducts have different characteristics that make them more or less compatible with undergoing an anaerobic digestion process. Moreover, their availability in terms of volume must be adequate to allow their sustainable exploitation at a full scale. The applicability of coffee byproducts must thus be supported by both an experimental and modeling investigation. This integrated approach represents the novelty of the present work, where experimental analyses are matched with the application of modeling techniques to evaluate the two aspects together (productivity and scalability).

In order to perform an evaluation of the proposed technical solutions concerning biogas plants, a computational model developed at Politecnico di Torino Department of Environment, Land, and Infrastructure Engineering, called MCBioCH4, was employed. This model is able to integrate laboratory tests and to support the choice of technical solutions that maximize the energy efficiency and environmental sustainability of the process.

\section{Materials and Methods}

\subsection{Substrate Origin}

In this work, six coffee-roasting byproducts were tested in order to evaluate their anaerobic biodegradability. Table 2 shows the production of the tested substrates (raw powder from green coffee, pellets, and powder from the roasted coffee) generated by two different plants. Both analyzed plants are managed by the same Italian coffee producer.

Table 2. Annual (2016) production of byproducts from the roasting process of green coffee in two analyzed plants.

\begin{tabular}{cccc}
\hline PLANTS & Pellets (ton) & Green Coffee Powder (ton) & Roasted Coffee Powder (ton) \\
\hline Plant A & 780 & 70 & 280 \\
Plant B & 766 & 155 & 627 \\
\hline
\end{tabular}

\subsection{Substrate Characterization}

Standard methods [18] were employed for determining total solids (TS) and volatile solids (VS). CHNS equipment was adopted for the elemental analysis concerning carbon, hydrogen, nitrogen, oxygen, and sulfur. Mahler's bomb was used for determining the higher heating value (HHV) of the three matrixes according to the calorimetric method. The theoretical methane potential values were calculated, taking into account Equation (1) [19].

$$
B_{\text {th }}=V S_{\text {in }} \times \frac{C O D_{\text {in }}}{V S_{\text {in }}} \times 0.350\left[\frac{\mathrm{Nm}^{3}}{\mathrm{kgCOD}}\right]
$$

Given the CHNS analysis of a generic compound $\left(\mathrm{C}_{\mathrm{a}} \mathrm{H}_{\mathrm{b}} \mathrm{O}_{\mathrm{c}} \mathrm{N}_{\mathrm{d}}\right)$, the $C O D_{\text {in }} / V S_{\text {in }}$ ratio was calculated, as in Equation (2):

$$
\frac{C O D_{\text {in }}}{S V_{\text {in }}}=\frac{8 \times(4 a+b-2 c-3 d)}{(12 a+b+16 c+14 d)}
$$

In Equation (2), $C O D_{\text {in }}$ is the concentration of the fed substrate in terms of chemical oxygen demand, and 0.350 is the maximum theoretical conversion of chemical oxygen demand (COD) to methane at standard condition $\left(0^{\circ} \mathrm{C}, 10^{5}\right.$ bar $)[20]$.

\subsection{Anaerobic Digestion Tests}

Two successive phases of experimentation were carried out: The first involved the laboratory study of the three matrices individually; the second phase considered two different mixes of the three matrices. The fractions composing the mixes are linked to the annual quantities produced in 
Plant A and Plant B. In particular, the mix from plant A is composed of $6.2 \%$ green coffee powder, $26.3 \%$ roasted coffee powder, and $67.5 \%$ pellets. The Plant B mix is composed of $9.2 \%$ green coffee powder, $42.9 \%$ roasted coffee powder, and $47.9 \%$ pellets.

Thermophilic conditions $\left(55^{\circ} \mathrm{C}\right)$ and laboratory scale were adopted for the anaerobic digestion tests performed in duplicate. In any case, the laboratory tests ended when the daily methane production was less than $1 \%$ of the cumulative biogas production, as advised in the German Guidelines VDI 4630 [21]. The thermophilic condition was selected among mesophilic conditions as a light increase of biogas production was recorded, but an increase in kinetics was also observed, allowing the digestion of the organic matter in around 20 days instead of 28 (data not showed).

The test performed on the single substrates had a total duration of 18 days, while the second phase test had a duration of 35 days. The first phase of AD tests was performed in batch mode using 8-2.8 L lab-digesters placed in a thermostatic bath. Each digester had a working volume of 2.0 L. The anaerobic environment was prepared by filling head-space digesters with nitrogen gas. Each digester was manually mixed for $60 \mathrm{~s}$ once a day. Two of the 8 anaerobic digesters were blank tests used to evaluate the amount of methane generated by the inoculum. In blank tests, the volume of inoculum added to the reactors was the same as that used for the tests with substrates.

The second phase of AD tests was performed in fed-batch mode using 6-6.0 L lab-digesters placed in a thermostatic bath. Each digester had a working volume of $4.0 \mathrm{~L}$. The anaerobic environment was prepared by filling head-space digesters with nitrogen gas. Each digester was manually mixed for $60 \mathrm{~s}$ once a day ( $60 \mathrm{rpm})$. Two of the 6 anaerobic digesters were blank tests used to evaluate the amount of methane generated by the inoculum.

The produced biogas in each test was collected in a gas bag (maximum volume $5 \mathrm{~L}$ ), and the composition $\left(\mathrm{CH}_{4}, \mathrm{CO}_{2}, \mathrm{O}_{2}\right.$, others) was recorded every working day, from Monday to Friday, for the whole duration of the test [22].

The inoculum was provided by the ACEA plant, located in the Turin area, where the thermophilic digestion process is applied to the organic fraction of municipal solid waste. A biogas analyzer (Biogas Check, Geotechnical Instruments Ltd., Coventry, UK) was employed to determine biogas composition in terms of $\mathrm{CH}_{4}, \mathrm{CO}_{2}$, and $\mathrm{O}_{2}$, flushing $500 \mathrm{~mL}$ of the collected biogas. After the biogas characterization, the residual volume of the biogas was measured using the residual gas for the displacement of water. The volume of methane was calculated by multiplying the percentage of methane for the biogas volume in normal conditions.

\subsection{Model Analysis of Batch and Fed-Batch Assay Results}

Batch and fed-batch AD tests are commonly employed to assess the methane production of a substrate. However, the results of those tests depend on several parameters: the activity and origin of the inoculum, temperature, digestion time, and the ratio between the inoculum substrate and the hydrolysis coefficient. In order to compare different substrates or digestion modes in terms of methane production, it is necessary to identify some parameters that are capable of fully describing the biological process [20]. Because of this, the methane production data obtained from the batch and fed-batch tests were used to assess biochemical methane potential $\left(\mathrm{B}_{0}\right)$ and the first-order hydrolysis rate constant $(\mathrm{k})$ of the studied matrix and related mixes.

$\mathrm{B}_{0}$ is the maximum amount of methane that a substrate can produce after an infinite time; $k$ is a first-order kinetic constant that is able to model the disintegration process. The anaerobic digestion consists of four steps: hydrolysis, acidogenesis, acetogenesis, and methanogenesis. Hydrolysis is the first step, and it is the only one where the microorganisms are not directly involved. This process is merely a surface phenomenon in which the particulate and polymeric matters are degraded through the action of esoenzymes. After hydrolysis, the smaller molecules produced by the process can cross the cell barriers [23]. The disintegration-hydrolysis phase is generally the rate-limiting step during the 
AD of particulate/complex substrates [24]. The evolution of cumulative methane production during a batch $\mathrm{AD}$ test $\mathrm{B}(\mathrm{t})$ can be modeled according to a first-order reaction rate, as in Equation (3).

$$
B(t)=V S \times V \times B_{o} \times\left(1-e^{-k t}\right)
$$

where the parameters not previously mentioned are the following: VS is the concentration of volatile solids, and $V$ is the working volume of the anaerobic reactor. In addition, it is also possible to estimate the absolute biodegradation $(Y)$, as defined in Equation (4).

$$
Y=\frac{B_{0}}{B_{t h}}[\%]
$$

Known $Y$, the cumulative methane production obtained during a fed-batch test, can be modeled according to the system of equations reported in Equation (5).

$$
\left\{\begin{array}{c}
\frac{d Y V S(t)}{d t}=\frac{M_{i n}(t)}{V}-k \times Y \times V S(t) \\
B_{d}(t)=Y \times V S(t) \times k \times B_{o} \times V
\end{array}\right.
$$

$M_{i n}$ is the $i$-th mass of substrate in terms of volatile solids fed during the fed-batch tests. The first-order kinetic models (Equations (3) and (5)) were implemented in Simulink-MATLAB ${ }^{\circledR}$ 2020a software (Mathworks Inc., 1 Apple Hill Drive, Natick, Middlesex, MA, USA) to search for $B_{0}$ and $k$.

The optimal set of $\mathrm{B}_{0}$ and $k$ values was obtained by minimizing the objective function (J), that is, the residual sum of squares (RSS) between the measured data and the model-predicted data, as in Batstone and coauthors $[25,26]$.

Moreover, the $B_{0}$ and $k$ parameters obtained from batch tests carried out on the three coffee byproducts were validated. Those parameters were used to predict the cumulative methane production of the two mixes of the anaerobically tested matrices.

\subsection{Computation Model for Evaluation of Biomethane Solutions}

A preliminary assessment of the full-scale applicability of the recovery process was carried out by introducing the results obtained in the laboratory into a biogas/biomethane evaluation model developed by the authors.

The MCBioCH4 model (the acronym of the biomethane computational model) takes into account three aspects:

- to obtain data concerning the productivity of biogas plants with the related possible gas flow rates;

- to know the energy consumption of the plant and the related remaining energy flows, which is useful for economic valorization (electrical- and/or thermal-produced energy, biomethane for transport use, and/or gas distribution grid);

- to take into account the total environmental impact of the system.

The design of MCBioCH4 was specifically addressed to the preliminary assessment and comparison of different potential plant configurations and technological solutions based on the implementation of default datasets derived from extended bibliographic research. The computing code was entirely developed using MATLAB ${ }^{\circledR}$ 2020a software (Mathworks Inc., 1 Apple Hill Drive, Natick, Middlesex, MA, USA). MCBioCH4 is composed of three different modules for the calculation of mass, energy, and greenhouse gas (GHG) balance, respectively. The code estimates the production of biogas and the relevant losses that may be expected in the system.

Energy conversion through biogas combustion and/or biomethane production is simulated by the model. If the biogas combustion option is selected, the model simulates combustion in commercial combined heat and power plants (CHPs). The amount of thermal energy recovery can be specified. If the biomethane option is selected, the user is allowed to select the upgrading technology, as well as customize the efficiency and parasitic consumption of the upgraded system. 
The following technologies are taken into account: pressure swing absorption, pressurized water scrubbing, chemical absorption with amine, and membrane permeation. The model is also able to simulate other upgrading technologies such as cryogenic separation. The model is equipped with default parameters that, alternatively, may be customized by the user. The results of the model are

- Mass and energy balance of the system;

- The greenhouse gas balance of the system, referred to an equivalent traditional system with fossil fuels.

For more details, refer to Ravina et al. [27]. The MCBioCH4 model was recently applied to the evaluation of the anaerobic digestion of mixed agriculture-zootechnic waste matter [28] and wastewater sludge treatment $[29,30]$.

For the simulation of the case under study, the experimental results of thermophilic anaerobic digestion tests were considered. Full-scale methane production for Plant A and Plant B was estimated by considering the substrate production reported in Table 2 . Regarding methane energy conversion, simulations were repeated, considering both direct onsite biogas combustion and biomethane upgrading. For the first option, an electrical efficiency of the reciprocating biogas engines equal to 0.40 was assumed. The availability of $8000 \mathrm{~h} / \mathrm{y}$ was assumed for the CHP unit. For the biomethane option, considering the Italian legislation on incentives for biomethane production [31], an injection into the national gas grid was considered as the final destination. A biogas upgrading technology with selective membranes (MBs) was simulated. The main input factors and values considered in the simulations are reported in Table 3. Due to the absence of direct measurements, the amount of methane lost, the energy autoconsumption, and the efficiency of the system were estimated by using the default parameters set by the model. For more information on these parameters, refer to [27]. Equivalent $\mathrm{CO}_{2}$ emission factors were taken by [32].

Table 3. Input values and parameters implemented in the MCBioCH4 model.

\begin{tabular}{lcc}
\hline \multicolumn{1}{c}{ Input Parameter/Value } & Plant A & Plant B \\
\hline CH4 loss from digestion and conversion processes (\%) & \multicolumn{2}{c}{1.6} \\
Energy autoconsumption for thermal process sustainment $(\mathrm{MWh} / \mathrm{y})$ & 181 & 845 \\
Electricity autoconsumption, biogas section (MWh/y) & 30.2 & 114 \\
Upgrading system efficiency (\%) & \multicolumn{2}{c}{98.6} \\
Electricity autoconsumption, upgrading system $(\mathrm{MWh} / \mathrm{y})$ & 22.9 & 109.32 \\
Emission factor for natural gas consumption/substitution $\left(\mathrm{gCO}_{2 \mathrm{e}} / \mathrm{kWh}\right)$ & 206 & 206 \\
Emission factor for electricity substitution (Italian grid) $\left(\mathrm{gCO}_{2 \mathrm{e}} / \mathrm{kWh}\right)$ & 337 & 337 \\
\hline
\end{tabular}

\section{Results}

\subsection{Substrate Characterization}

The CHNS-O, $\mathrm{B}_{\text {th }}, \mathrm{HHV}$, TS, and VS analyses are reported in Table 4. The results showed high TS and VS concentration values in the analyzed substrates. Moreover, the green coffee powder HHV had a value of $50.7 \%$ higher than the other two tested byproducts.

Table 4. Elemental characterizations of the three considered matrices.

\begin{tabular}{cccccccccc}
\hline Matrix & N (\%) & $\mathbf{C ~ ( \% ) ~}$ & $\mathbf{H ~ ( \% )}$ & $\mathbf{S ~ ( \% )}$ & $\mathbf{O ~ ( \% )}$ & $\begin{array}{c}\mathbf{B}_{\text {th }} \\
\mathbf{( N m}^{\mathbf{3} / \mathbf{k g V S})}\end{array}$ & $\begin{array}{c}\text { HHV } \\
\mathbf{( M J} / \mathbf{k g})\end{array}$ & TS (\%) & VS (\%) \\
\hline Pellets & 3.2 & 50.6 & 6.5 & 0.1 & 39.6 & 0.50 & 13.9 & 93.9 & 86.1 \\
Roasted coffee powder & 3.1 & 54.2 & 6.9 & 0.0 & 35.9 & 0.55 & 12.8 & 97.4 & 92.8 \\
Green coffee powder & 2.6 & 50.3 & 6.4 & 0.0 & 40.8 & 0.49 & 19.9 & 90.7 & 84.4 \\
\hline
\end{tabular}




\subsection{Anaerobic Digestion Tests}

Figures 1 and 2 show the experimental and simulated biochemical methane production profiles by the first-order kinetic model, which disclose the satisfactory fit of methane production data to this type of model. The results obtained in the first and second phases of anaerobic digestion tests, conducted in batch and fed-batch mode, are reported in Table 5. This table shows the biochemical methane potential $\left(\mathrm{B}_{0}\right)$ and the absolute biodegradability $(\mathrm{Y})$.

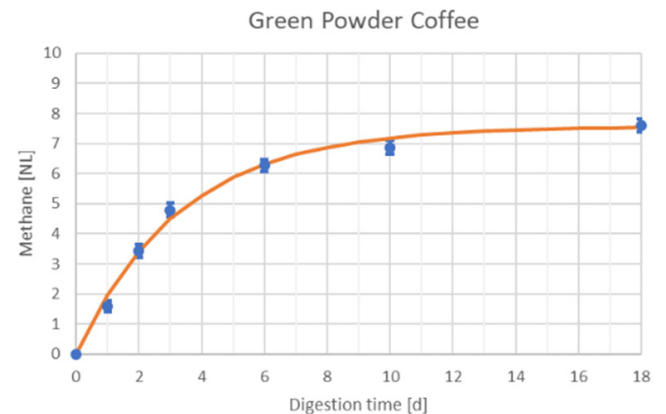

(a)

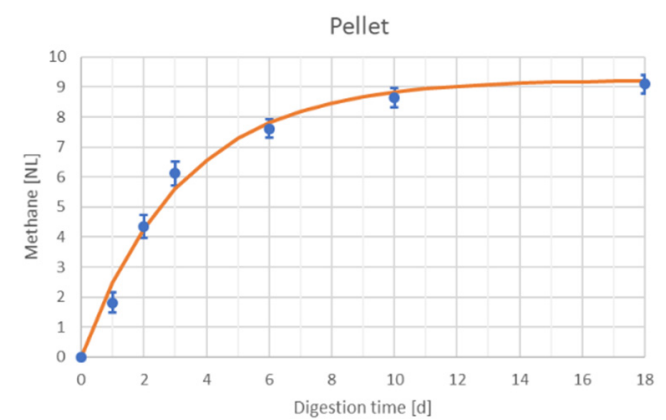

(b)

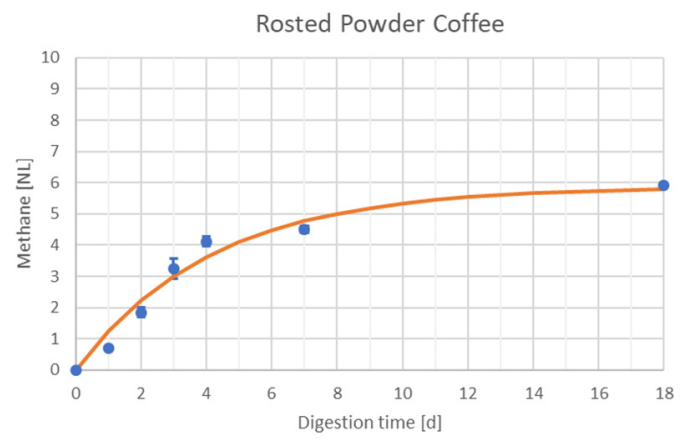

(c)

Figure 1. Anaerobic digestion $(\mathrm{AD})$ batch tests. Measured points and simulated biochemical methane production curves. (a) green powder coffee; (b) pellet; (c) rosted powder coffee.

Mix 1 - Plant A

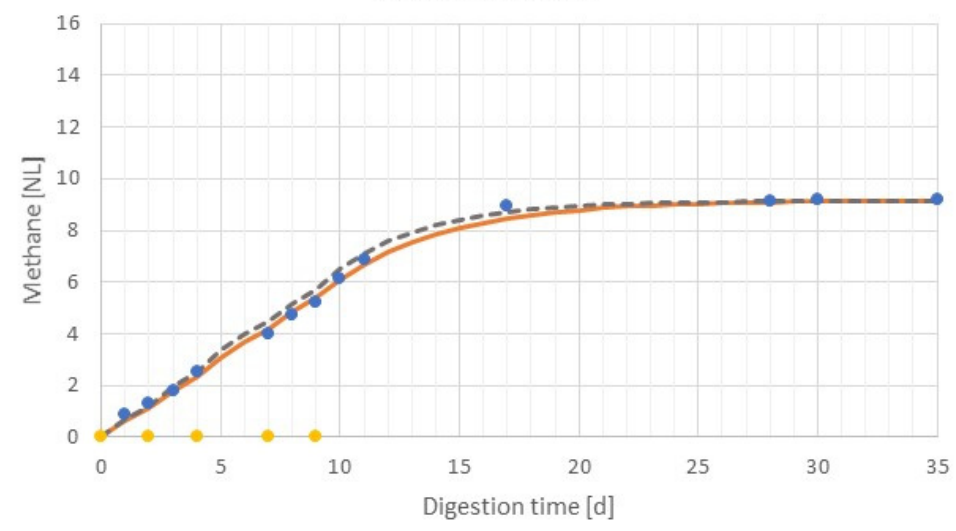

(a)

Figure 2. Cont. 
Mix 2 - Plant B

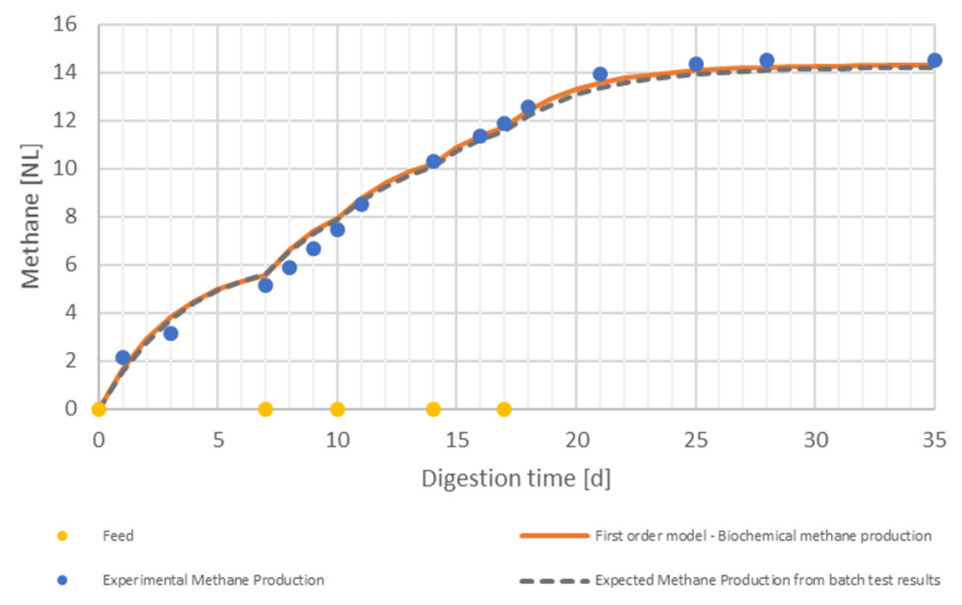

(b)

Figure 2. AD fed-batch tests. Measured points, simulated biochemical methane production curves, and expected biochemical methane production curves (validation of batch test results). (a) mix 1; (b) $\operatorname{mix} 2$.

Table 5. Results of batch anaerobic digestion tests performed on a single matrix and mixed matrices.

\begin{tabular}{lccc}
\hline \multicolumn{1}{c}{ Matrix } & $\begin{array}{c}\mathbf{B}_{\mathbf{0}} \\
\left.\mathbf{( N m}^{\mathbf{3}} \mathbf{k g V S}\right)\end{array}$ & $\begin{array}{c}\mathbf{k} \\
\mathbf{( 1 / d )}\end{array}$ & $\begin{array}{c}\mathbf{Y} \\
\mathbf{( - )}\end{array}$ \\
\hline Pellets & $0.22( \pm 0.01)$ & 0.31 & 0.44 \\
Roasted coffee powder & $0.33( \pm 0.01)$ & 0.24 & 0.60 \\
Green coffee powder & $0.18( \pm 0.01)$ & 0.30 & 0.37 \\
Plants A (mixed matrix) & $0.24( \pm 0.01)$ & 0.26 & 0.45 \\
Plants B (mixed matrix) & $0.27( \pm 0.02)$ & 0.28 & 0.50 \\
\hline
\end{tabular}

In Table 5 , it is possible to notice that the biochemical methane production $\mathrm{B}_{0}$ was gathered from roasted coffee power, then there is the pellets' specific methane production, and, at last, the lowest value is the one belonging to green coffee powder. In all the performed experiments, the methane concentration in biogas was about equal to $50 \%$ b.v.

The results of the $\mathrm{AD}$ tests carried out on the two mixes of byproducts are also reported in Table 5 . The results show that the methane produced by the two mix tests are similar and linked to the SMPs of the three substrates digested in the first phase. Figure 2 displays the obtained cumulative methane productions during fed-batch $\mathrm{AD}$ tests. The same graphs show the expected cumulative methane productions found, considering the batch test results. These curves were calculated using Equation (5). In depth, $B_{0}$ and $k$ values were assumed from the weighted averages values of $B_{0}$ and $k$, relative to each coffee byproduct tested, found during the batch tests; the results are reported in Table 5. Figure 2 displaces, in both the graphs, good accordance between the simulated biochemical methane production profiles by the first-order kinetic model and the expected one. Therefore, the results obtained in the batch tests are consistent and validated; in both fed-batch AD tests, they were able to predict the cumulative methane production trend.

According to the authors' knowledge, there is no published research concerning the anaerobic digestion of coffee byproducts in thermophilic conditions, even though these kinds of residues are produced in high amounts in countries around the world. A recent study, Fiore et al. [11], has evaluated the specific biogas potential (SBP) of several types of food industry waste, also considering coffee byproducts. Anaerobic digestion was performed at the laboratory scale, with fed-batch mode and mesophilic conditions. Fiore et al. [8] measured the specific biogas production (SBP equal to 
$0.48 \mathrm{Nm}^{3} / \mathrm{kg} \mathrm{VS} \mathrm{CH}_{4} /$ biogas $\left.=0.55\right)$ of coffee byproducts $(60 \%$ pellets, $40 \%$ roasted coffee powder), similar to the results presented in this work.

Baêta et al. [33] obtained a specific methane potential (SMP) for coffee husks equal to $0.063 \mathrm{Nm}^{3} / \mathrm{kg}$ COD in mesophilic conditions by means of a BMP test; this result is lower than the results presented in this work (see Table $5 ; 0.14 \mathrm{Nm}^{3} / \mathrm{kg}$ VS or $0.096 \mathrm{Nm}^{3} / \mathrm{kg} \mathrm{COD)}$ ).

Malovè et al. [31] reported a $B_{0}$ for untreated pellets equal to NL/g VS, but this parameter reached a value three times higher by means of the adoption of a thermoalkali pretreatment with $\mathrm{NaOH}$, heated for $3 \mathrm{~h}$ at $90{ }^{\circ} \mathrm{C}$. The $\mathrm{B}_{0}$ of treated coffee pellets in Malovè et al. [31] was similar to this work's results.

Lastly, Battista et al. [34] reported the specific methane production of a mixture made by pellets, roasted coffee powder, and green coffee powder (ratio 3:1:1), anaerobically digested $\left(0.011 \mathrm{Nm}^{3} / \mathrm{kg} \mathrm{VS}\right.$ ). The result was much lower than the value obtained in this work, but the volatile solids reduction $(24.92 \%)$ was similar to the experimental data.

\subsection{Full-Scale Simulation Results}

A preliminary analysis was performed in order to evaluate the feasibility of a full-scale anaerobic digestion plant for each industrial site. The results are shown in Table 6.

Table 6. Preliminary technical analysis.

\begin{tabular}{cccc}
\hline Plants & $\begin{array}{c}\text { Methane } \\
\left(\mathbf{N m}^{\mathbf{3}} \mathbf{y}\right)\end{array}$ & $\begin{array}{c}\text { Electrical Energy } \\
\mathbf{( k W h / y )}\end{array}$ & $\begin{array}{c}\text { Electrical Power of Biogas Engine } \\
\mathbf{( k W )}\end{array}$ \\
\hline Mix from Plant A & 150,000 & 600,000 & 75 \\
Mix from Plant B & 226,000 & 900,000 & 113 \\
\hline
\end{tabular}

The results reported in Table 6 were also implemented in the MCBioCH4 model to simulate biomethane production as an alternative solution to biogas direct combustion. The results obtained by running the mass, energy, and environmental modules for the two plants are reported in Figures 3 and 4 and Table 7. The mass balance of Plant A and Plant B is reported in Figure 3. In this figure, the most relevant material flows are reported, which include both production and loss terms. Starting from an amount of input substrates (3.09 and 4.24 t/d for Plant A and Plant B, respectively), a low amount of biogas equal to $0.55 \mathrm{t} / \mathrm{d}$ and $0.78 \mathrm{t} / \mathrm{d}$ is produced. A limited amount of the produced biogas is lost in fugitive emissions from the system $(1.7$ and $2.3 \mathrm{~kg} / \mathrm{d}$ for Plant $A$ and Plant $B$, respectively). The net biogas flow is sent to the upgrading system, and biomethane is obtained. The expected biomethane production is 0.157 and $0.222 \mathrm{t} / \mathrm{d}$ for Plant A and Plant B, respectively. Due to the inefficiency of the separating system, a limited amount of the methane $(2.1$ and $3.2 \mathrm{~kg} / \mathrm{d}$ for Plant A and Plant $\mathrm{B}$, respectively) remains on the off-gas and is emitted into the atmosphere.

The mass balance of Plant A and Plant B is reported in Figure 4. In this figure, outgoing flows refer to the production terms and ingoing flows refer to the consumption terms. As reported in this figure, the AD system necessitates external sources of thermal energy and electricity. This indeed represents a limitation of the biomethane option. Thermal energy (186 and $262 \mathrm{MWh} / \mathrm{y}$ for Plant A and Plant B, respectively) is needed to maintain the digester's temperature at a constant value, as well as to preheat the incoming substrates. This flow represents the highest consumption term. Electricity from the national grid is also needed by the auxiliary systems of the plant ( 31.5 and $44.5 \mathrm{MWh} / \mathrm{y}$ for Plant A and Plant B, respectively). The gross biogas energy content amounts to 830 and $1173 \mathrm{MWh} / \mathrm{y}$ for Plant A and Plant B, respectively. After the upgrading process, the net energy content of the produced biomethane is slightly lower than the gross amount, as part of the methane is lost in the off-gas. Additional consumption of electricity is also needed (23.9 and $33.7 \mathrm{MWh} / \mathrm{y}$ for Plant A and Plant $B$, respectively), while a small amount of heat is recovered from the biogas compression stage. Net energy production amounts to 818 and $1157 \mathrm{MWh} / \mathrm{y}$ for Plant A and Plant B, respectively. 
The environmental balance reported in Table 7 shows that avoided emissions for the substitution of natural gas are higher than the emissions produced for process maintenance. An emission reduction of $81 \mathrm{t}$ and $114.6 \mathrm{tCO}_{2 \mathrm{eq}} / \mathrm{y}$ is estimated for Plant A and Plant B, respectively. This means that under the sustainability point of view, the production of biomethane would allow optimum exploitation of the energy contained in the waste matter. GHG emission for substrate handling and fugitive losses amount to 30.7 and $43.4 \mathrm{t} \mathrm{CO}_{2 \mathrm{eq}} / \mathrm{y}$ for Plant $\mathrm{A}$ and Plant B, respectively, and thus contribute significantly to the emission balance.

The results of the preliminary simulation show that, in principle, a full-scale implementation of the coffee waste biogas process is technically feasible and environmentally sustainable. This latter fact is generally recognized for the so-called third-generation biogas systems, i.e., systems that focus on waste valorization rather than biomass exploitation [35]. Considering the subsidies recently introduced by Italian regulations [36], it is expected that the presented configurations are also economically feasible solutions. Nevertheless, the economic balance of the proposed solutions will be evaluated in future studies.

Table 7. Output of the biomethane simulation with the MCBioCH4 model.

\begin{tabular}{lcc}
\hline \multicolumn{1}{c}{ Input Parameter/Value } & Plant A & Plant B \\
\hline Gross biogas energy content $(\mathrm{MWh} / \mathrm{y})$ & 830.4 & 1173.6 \\
Net useful energy in biomethane $(\mathrm{MWh} / \mathrm{y})$ & 818.5 & 1157.0 \\
Thermal energy autoconsumption covered by external source $(\%)$ & 100 & 100 \\
Electricity autoconsumption covered by external source $(\%)$ & 100 & 100 \\
GHG emission produced substrates handling and fugitive $\mathrm{CH}_{4}$ loss $\left(\mathrm{t} \mathrm{CO}_{2 \mathrm{e}} / \mathrm{y}\right)$ & 30.7 & 43.4 \\
GHG emission produced-electricity autoconsumption $\left(\mathrm{t} \mathrm{CO}_{2 \mathrm{e}} / \mathrm{y}\right)$ & 18.7 & 26.4 \\
GHG emission produced-natural gas for thermal autoconsumption $\left(\mathrm{t} \mathrm{CO}_{2 \mathrm{e}} / \mathrm{y}\right)$ & 38.2 & 54.0 \\
Total GHG emissions produced & 87.6 & 123.8 \\
Total GHG emissions avoided for natural gas replacement $\left(\mathrm{t} \mathrm{CO}_{2 \mathrm{e}} / \mathrm{y}\right)$ & -168.7 & -238.4 \\
GHG emission balance $(\mathrm{t} \mathrm{CO} 2 \mathrm{e} / \mathrm{y})$ & -81.0 & -114.6 \\
\hline
\end{tabular}

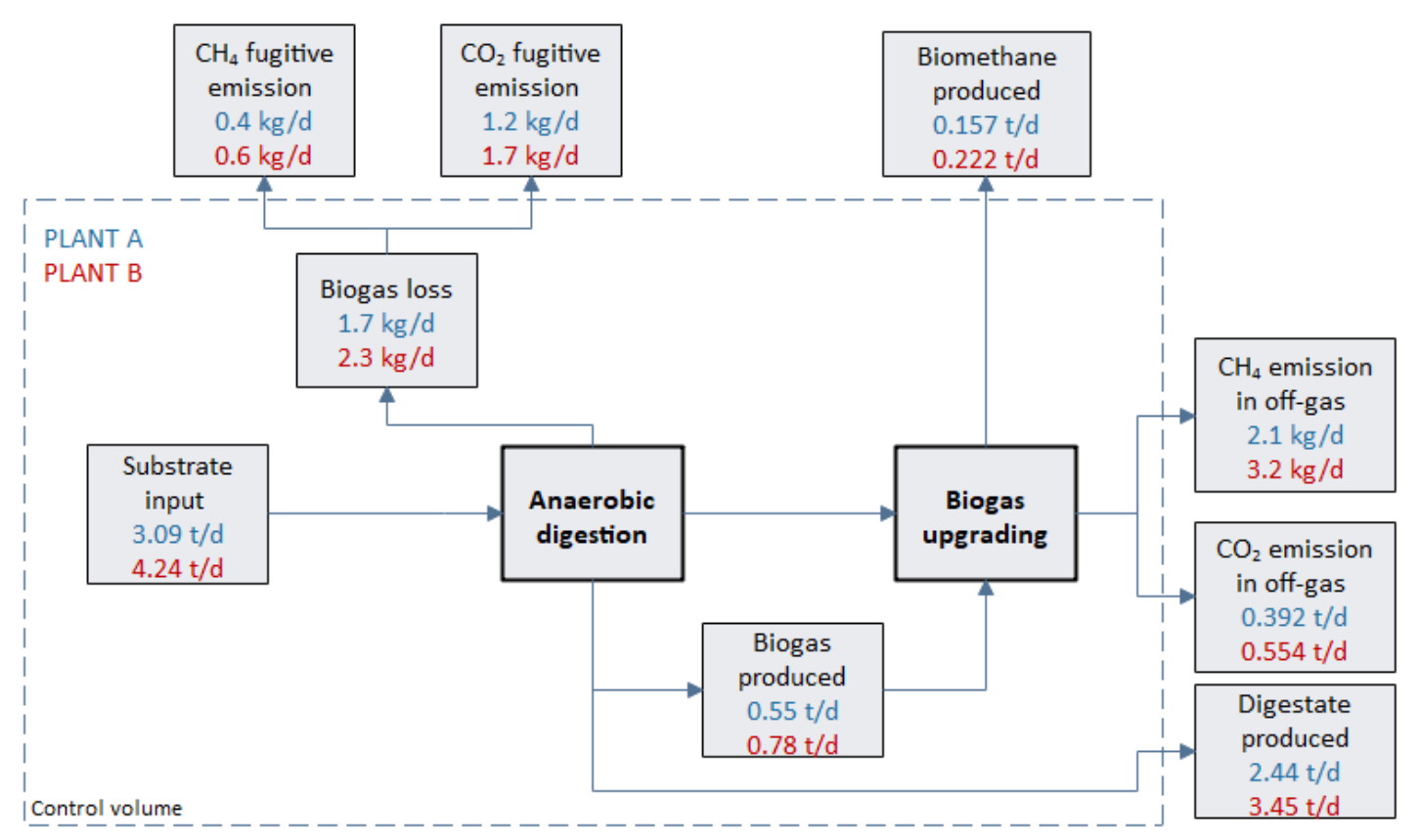

Figure 3. Mass balance of Plant A (in blue) and Plant B (in red). 


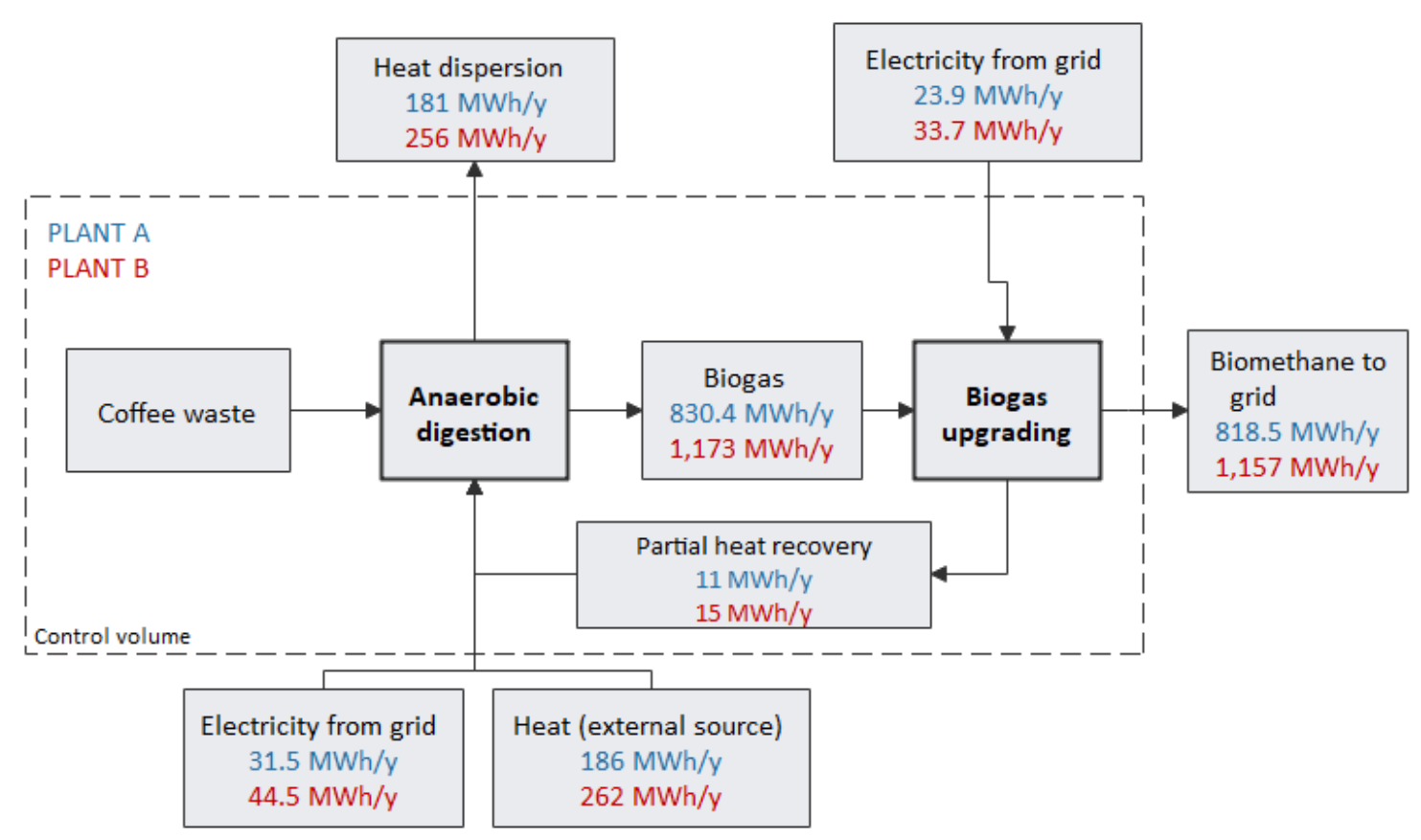

Figure 4. Energy balance of Plant A (in blue) and Plant B (in red).

\section{Conclusions}

In this work, thermophilic anaerobic digestion tests were carried out on two byproduct mixes from the green coffee roasting process. The fractions composing the mixes are linked to the annual quantities produced in Plant A and Plant B. The resulting $B_{0}$ was 0.24 and $0.27 \mathrm{Nm}^{3} / \mathrm{kgVS}$ from Mix A and Mix B, respectively. Starting from these results, the application of a full-scale anaerobic digestion plant was studied. Plant A could produce $150,000 \mathrm{Nm}^{3} \mathrm{CH}_{4} / \mathrm{y}$, while Plant B could produce $226,000 \mathrm{Nm}^{3} / \mathrm{y}$. The power production of the two engines would be equal to 75 and $113 \mathrm{kWe}$, respectively, in Plant A and Plant B.

Output values from the laboratory were used as input for the $\mathrm{MCBioCH}_{4}$ model in order to evaluate an alternative valorization possibility for biogas, i.e., the production of biomethane. The results of the preliminary simulation showed that, in principle, a full-scale implementation of the coffee waste biogas process is technically feasible and environmentally sustainable. A net energy production of 818.5 and $1157 \mathrm{MWh} / \mathrm{y}$ was estimated for Plant A and Plant B, respectively. The produced biomethane was assumed to replace an equivalent amount of fossil natural gas, corresponding to an emission reduction of 81 and $114.6 \mathrm{tCO}_{2 \mathrm{e}} / \mathrm{y}$ for Plant $\mathrm{A}$ and Plant $\mathrm{B}$, respectively.

A preliminary evaluation of the possible solutions for energy recovery from green coffee roasting was performed in this study by means of an integrated environmental and modeling approach. This method may be applied to other similar cases.

Author Contributions: Conceptualization, G.C., A.C., M.R., D.P., and V.A.R.; methodology, G.C., A.C., M.R., D.P., and V.A.R.; software, M.R.; validation, M.R. and D.P.; formal analysis, G.C., A.C., and V.A.R.; investigation, G.C., A.C., M.R., D.P., and V.A.R.; resources, M.Z.; data curation, G.C., A.C., M.R., D.P., and V.A.R.; writing-original draft preparation, G.C., A.C., and M.R.; writing-review and editing, G.C., A.C., M.R., and D.P.; visualization, D.P.; supervision, D.P., V.A.R., and M.Z.; project administration, D.P. and V.A.R.; funding acquisition, M.Z. All authors have read and agreed to the published version of the manuscript.

Funding: This research received no external funding.

Conflicts of Interest: The authors declare no conflict of interest. 


\section{Abbreviations}

$\begin{array}{ll}\text { AD } & \text { anaerobic digestion } \\ \mathrm{B}_{\text {th }} & \text { theoretical biochemical methane potential } \\ \mathrm{B}_{0} & \text { biochemical methane potential } \\ \mathrm{CHNS} & \text { carbon hydrogen nitrogen sulfur } \\ \mathrm{CHP} & \text { combined heat and power } \\ \mathrm{COD} & \text { chemical oxygen demand } \\ \mathrm{CO}_{2 \text { eq }} & \text { equivalent carbon dioxide } \\ \mathrm{CRY} & \text { cryogenic separation } \\ \mathrm{HHV} & \text { higher heating value } \\ \mathrm{GHG} & \text { greenhouse gases } \\ \mathrm{k} & \text { first-order hydrolysis rate constant } \\ \text { MEA } & \text { chemical absorption with amine solutions } \\ \text { MB } & \text { membrane permeation } \\ \text { PSA } & \text { pressure swing absorption } \\ \text { PWS } & \text { pressurized water scrubbing } \\ \text { SBP } & \text { experimental biogas production } \\ \text { TS } & \text { total solids } \\ \text { VS } & \text { volatile solids } \\ \text { Y } & \text { absolute biodegradability }\end{array}$

\section{References}

1. Ruffino, B.; Zanetti, M.C. Present and future solutions of waste management in a candied fruit-jam factory: Optimized anaerobic digestion for on site energy production. J. Clean. Prod. 2017, 159, 26-37. [CrossRef]

2. Magaril, E.R.; Magaril, R.; Panepinto, D.; Genon, G.; Ravina, M.; Trushkova, L.; Zanetti, M.C. Production and utilization of energy and climate adaptation: Global tasks and local routes. Int. J. Sustain. Dev. Plan. 2017, 12, 1326-1337. [CrossRef]

3. Mussatto, S.I.; Machado, E.M.S.; Martins, S.; Teixeira, J.A. Production, Comosition and Application of Coffee and Its Industrial Residues. Food Bioprocess Technol. 2011, 4, 661-672. [CrossRef]

4. Franca, A.S.; Oliveira, L.S. Coffee Processing Solid Wastes: Current Uses and Future Prospectives. Agric. Wastes 2009, 9, 155-189.

5. Panepinto, D.; Riggio, V.A.; Campo, G.; Cerutti, A.; Zanetti, M.C. Analysis of two treatment technologies for coffee roasting matrixes: Combustion and anaerobic digestion. Clean Technol. Environ. Policy 2019, 21, 685-694. [CrossRef]

6. IIT: Dagli Scarti alla Bioplastica, la Sostenibilità è Energia. 2018. Available online: http://www.askanews.it/video/ 2018/03/30/iit-dagli-scarti-alla-bioplastica-la-sostenibilit\%c3\%a0-\%c3\%a8-tecnologia-20180330_video_12543414/ (accessed on 22 September 2020).

7. Kovalcik, A.; Kucera, D.; Matouskova, P.; Pernicova, I.; Obruca, S.; Kalina, M.; Enev, V.; Marova, I. Influence of removal of microbial inhibitors on PHA production from spent coffee grounds employing Halomonas halophila. J. Environ. Chem. Eng. 2018, 6, 3495-3502. [CrossRef]

8. Obruca, S.; Benesova, P.; Petrik, S.; Oborna, J.; Prikryl, R.; Marova, I. Production of polyhydroxyalkanoates using hydrolysate of spent coffee grounds. Process Biochem. 2014, 49, 1409-1414. [CrossRef]

9. Battista, F.; Barampouti, E.M.; Mai, S.; Moustakas, D.B.D.M.K.; Loizidou, M. Added-value molecules recovery and biofuels production from spent coffee grounds. Renew. Sustain. Energy Rev. 2020, 131, 110007. [CrossRef]

10. Petroff, A. London Buses are Being Powered by a New Fuel: Coffee. 2017. Available online: https://money.cnn. com/2017/11/20/technology/coffee-fuel-bus-london-bio-bean/index.html (accessed on 22 September 2020).

11. Fiore, S.; Ruffino, B.; Campo, G.; Roati, C.; Zanetti, M.C. Scale-up evaluation of the anaerobic digestion of food-processing industrial wastes. Renew. Energy 2016, 96, 949-959. [CrossRef]

12. Figueroa, G.A.; Homann, T.; Rawel, H.M. Coffee Production Wastes: Potentials and Perspectives. Food Sci. 2016, 1, 1014. 
13. Somnuk, K.; Eawlex, P.; Prateepchaikul, G. Optimization of coffee oil extraction from spent coffee grounds using four solvents and prototype-scale extraction using circulation process. Agric. Nat. Resour. 2017, 51, 181-189. [CrossRef]

14. Bessada, S.; Alves, R.C.; Oliveira, M.B.P. Coffee Silverskin: A Review on Potential Cosmetic Applications. Cosmetics 2018, 5, 5. [CrossRef]

15. Wang, H.; Chiang, P.C.; Cai, Y.; Li, C.H.; Wang, X.; Chen, T.L.; Wei, S.; Huang, Q. Application of Wall and Insulation Materials on Green Building: A Review. Sustainability 2018, 10, 3331. [CrossRef]

16. Cecchini, C. Bioplastics made from upcycled food waste. Prospects for their use in the field of design. Des. J. 2017, 20, S1596-S1610. [CrossRef]

17. Panepinto, D.; Genon, G. Analysis of the extrusion as a pretreatment for the anaerobic digestion process. Ind. Crop. Prod. 2016, 83, 206-212. [CrossRef]

18. American Public Health Association (APHA); American Water Works Association (AWWA); Water Environment Federation (WEF). Standard Methods for the Examination of Water and Wastewater, 21st ed.; APHA; AWWA; WEF: Washington, DC, USA, 2005; ISBN 978-0875530475.

19. Tchobanoglous, G.; Theisen, H.; Vigil, S.A. Integrated Solid Waste Management; McGraw-Hill International Editions; McGraw-Hill: New York, NY, USA, 1993; pp. 681-682.

20. Ruffino, B.; Cerutti, A.; Campo, G.; Scibilia, G.; Lorenzi, E.; Zanetti, M. Thermophilic vs. mesophilic anaerobic digestion of waste activated sludge: Modelling and energy balance for its applicability at a full scale WWTP. Renew. Energy 2020, 156, 235-248. [CrossRef]

21. VDI Standard: VDI 4630 Fermentation of Organic Materials. Characterization of the Substrate, Sampling, Collection of Material Data, Fermentation Tests. 2006, p. 92. Available online: http://www.vdi.eu/guidelines (accessed on 1 October 2017).

22. Ruffino, B.; Cerutti, A.; Campo, G.; Scibilia, G.; Lorenzi, E.; Zanetti, M. Improvement of energy recovery from the digestion of waste activated sludge (WAS) through intermediate treatments: The effect of the hydraulic retention time (HRT) of the first-stage digestion. Appl. Energy 2019, 240, 191-204. [CrossRef]

23. Van Lier, J.B.; Mahmaud, N.; Zeeman, G. Chapter 16: Anaerobic Wastewater Treatment. In Biological Wastewater Treatment: Processes, Modelling and Design; IWA Publishing: London, UK, 2008.

24. Zhen, G.; Lu, X.; Kato, H.; Youcai, Z.; Cheng, J. Overview of pretreatment strategies for enhancing sewage sludge disintegration and subsequent anaerobic digestion: Current advances, full-scale application and future perspectives. Renew. Sustain. Energy Rev. 2017, 69, 559-577. [CrossRef]

25. Batstone, D.J.; Pind, P.F.; Angelidaki, I. Kinetics of thermophilic, anaerobic oxidation of straight and branched chain butyrate and valerate. Biotechnol. Bioeng. 2003, 84, 195-204. [CrossRef]

26. Wei, W.; Zhou, X.; Wangab, D.; Sun, J.; Wang, Q. Free ammonia pre-treatment of secondary sludge significantly increases anaerobic methane production. Water Res. 2017, 118, 12-19. [CrossRef]

27. Ravina, M.; Castellana, C.; Panepinto, D.; Zanetti, M.C. MCBioCH4: A computational model for biogas and biomethane evaluation. J. Clean. Prod. 2019, 227, 739-747. [CrossRef]

28. Ravina, M.; Genon, G. Global and local emissions of a biogas plant considering the production of biomethane as an alternative end-use solution. J. Clean. Prod. 2015, 102, 115-126. [CrossRef]

29. Kiselev, A.; Magaril, E.R.; Magaril, R.; Panepinto, D.; Ravina, M.; Zanetti, M.C. Towards Circular Economy: Evaluation of Sewage Sludge Biogas Solutions. Resources 2019, 8, 91. [CrossRef]

30. Borzooei, S.; Campo, G.; Cerutti, A.; Meucci, L.; Panepinto, D.; Ravina, M.; Riggio, V.; Ruffino, B.; Scibilia, G.; Zanetti, M.C. Feasibility analysis for reduction of carbon footprint in a wastewater treatment plant. J. Clean. Prod. 2020, 271, 122526. [CrossRef]

31. Malave, A.C.; Bernardi, M.; Fino, D.; Ruggeri, B. Multistep anaerobic digestion (MAD) as a tool to increase energy production via H2 p CH4. Int. J. Hydrogen Energy 2015, 40, 5050-5061. [CrossRef]

32. Institute for Environmental Protection and Research. Greenhouse Gas Emission Factors in the National Electricity Sector and in Major European Countries. Available online: http://www.isprambiente.gov.it/ files2019/pubblicazioni/rapporti/R_303_19_gas_serra (accessed on 22 September 2020).

33. Baêta, B.E.L.; de Miranda Cordeiro, P.H.; Passos, F.; Gurgel, L.V.A.; de Aquino, S.F.; Fdz-Polanco, F. Steam explosion pretreatment improved the biomethanization of coffee husks. Bioresour. Technol. 2017, 245, 66-72. [CrossRef]

34. Battista, F.; Fino, D.; Mancini, G. Optimization of biogas production from coffee production waste. Bioresour. Technol. 2016, 200, 884-890. [CrossRef] 
35. Paolini, V.; Petracchini, F.; Segreto, M.; Tomassetti, L.; Naja, N.; Cecinato, A. Environmental impact of biogas: A short review of current knowledge. J. Environ. Sci. Heal. Part A 2018, 53, 899-906. [CrossRef] [PubMed]

36. Ministero dello Sviluppo Economico. Incentivazione dell'Energia Elettrica Prodotta da Fonti Rinnovabili Diverse dal Fotovoltaico; GU n.150 of 29-6-2016; Ministero dello Sviluppo Economico: Rome, Italy, 2016.

(C) 2020 by the authors. Licensee MDPI, Basel, Switzerland. This article is an open access article distributed under the terms and conditions of the Creative Commons Attribution (CC BY) license (http://creativecommons.org/licenses/by/4.0/). 